
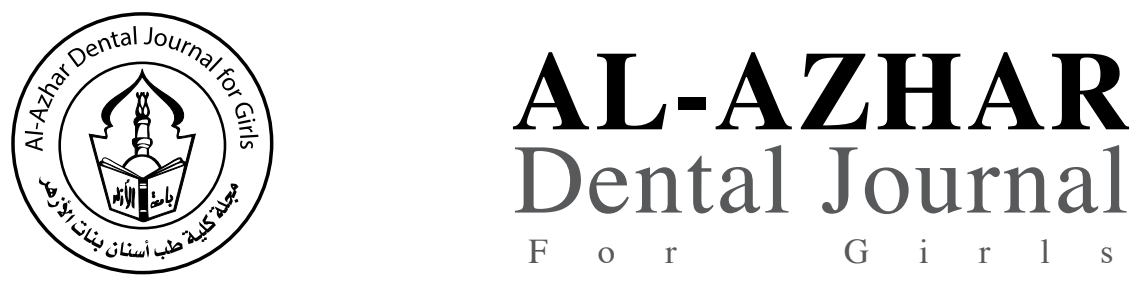

The Official Publication of The Faculty of Dental Medicine For Girls, Al-Azhar University Cairo, Egypt.

ADJ-for Grils, Vol. 4, No. 3, July (2017) - PP. 325:329

\title{
Effect of Balanced Occlusion Verses Lineal occlusion on Maximum Biting Force and Electromyographic Activity
}

\author{
Hala M Gamal Eldeen ${ }^{(1)}$
}

Codex : 38/1707

dentaljournal.forgirls@yahoo.com

\begin{abstract}
Ten completely edentulous male patients participated in this study. All patients received two implants in the canion region. For each patient two complete dentures were constructed. The artificial teeth of one denture was arranged according to full bilateral balanced occlusion, while in the other denture the teeth were arranged according to lineal occlusion concept. The maximum biting force and electromyographic activity were measured after one month from insertion of each denture. The result of the study found that there are no statistical significant differences between the two occlusal concepts. The study concluded that the lineal occlusion did not affect the value of the maximum biting force and electromyographic activity when compared to the bilateral balanced occlusion.
\end{abstract}

\section{INTRODUCTION}

Dentate status can affect diet, nutritional status, and general health. A complete maxillary denture can have an impact on taste and swallowing ability. Masticatory efficiency in complete denture wearers is approximately $80 \%$ lower than in people with natural dentition. Other factors that affect chewing ability include mobile teeth, bone resorption, reduced sensory perceptions, and motor impairment Every time opposing teeth contact there is a resultant force. Although this force may vary in magnitude and direction, it must always be resisted by supporting tissues. Some dentists believe there should be cusps on the teeth and that they must be in complete harmony with the dynamics of temporomandibular joint function. Other dentists believed that the teeth should not have cusps. There are numerous concepts, techniques, and philosophies concerning complete denture occlusion. 
The masticatory efficiency is defined as: the effort required to obtain a standard degree of comminution. While, masticatory performance is defined as a measure of the comminution of food attainable under standardized testing condition. ${ }^{(4)}$

The effects of implant-supported overdentures on masticatory function in patients with extremely resorbed mandibles was analyzed, and compared to masticatory function using 3 different types of implant treatment protocols. Masticatory function was assessed before and after treatment using a questionnaire a masticatory performance test, and structured interview. It was concluded that there was a significant improvement in masticatory function after implant overdenture treatment. However, the differences in masticatory function between the 3 modalities were not significant after treatment, regardless of the number of implants. ${ }^{(5)}$

The biting force is defined as, the result of muscular force applied on opposing teeth; the force created by the dynamic action of the muscles during the physiologic act of mastication; the result of muscular activity applied to opposing teeth. Sensitivity or pain of mucoperiosteum covering the mandibular edentulous ridg is often thought to limit bite forces in complete denture wearers. ${ }^{(4)}$

Bite force is gradually decreased from fully dentate subjects, subjects with fixed partial dentures, subjects with removable partial dentures and complete denture wear. ${ }^{(6)}$

The most commonly used devices for measuring bite force are piezoelectric elements or miniature strain gauges. Miniature strain gauges can be mounted, into transducers of various vertical heights, into a duplicated maxillary denture, into the mandibular denture at the denture-mucosa interface of the maxillary denture, or even into implant abutments. Furthermore, there are differences between samples studied with regard to age, number of participants, and the male-to-female ratio. In many studies, this information is even missing, which makes a reliable comparison impossible. ${ }^{(7)}$
When study group of subjects with implant-retained overdentures maximum bite force and masticatory performance were not related. This was caused by large variations in both maximum bite force and masticatory efficiency. ${ }^{(8-10)}$

\section{MATERIAL AND METHODS}

Ten completely edentulous male patients with age ranged from 45 to50 years participated in this study.The patients were selected with Angle class I jaw relationship. All patients received two screw implant fixtures in thecanion region (Dyna dental implant; Dyna Dental Engineering, Bergen op zoom, The Netherlands). The fixtures were installed according to the two stage surgical protocol and were kept submerged for 3 months.

For each patient two complete overdentures were constructed according to the occlusal pattern. The artificial teeth of the first denture were set up according to the lineal occlusal scheme the line of occlusal contact was placed in the mandibular denture, andin the second denturethe artificial teethwere set up according to bilateral balanced occlusion. The mandibular overdenture was retained by two ball and socket attachments connected to the two dental implants.

After three months the patients receivedone of thetow dentures and the patient was left for one month to be accustomed to the first denture. The electromyographic activity (EMG) for temporalis and masseter muscles and maximum biting force tests were carried out and recorded after adaptation period.

After finishing the EMG and maximum biting force tests, the first denture was removed and replaced by the second dentureand the patient was left for one month to be accustomed to the second denture. The electromyographic activity (EMG) for temporalis and masseter muscles and maximum biting force tests were repeated and recorded after adaptation period. 


\section{Electromyographic activity (EMG) for temporalis and masseter muscles:}

The patients were seated comfortably in an upright position. The masseter and anterior temporal muscles of both sides (left and right) were examined. Disposable silver/silver chloride bipolar surface electrodes (Duo-Trode; Myo-Tronics Inc., Seattle, WA, USA) were positioned on the muscular bellies parallel to muscular fibers. ${ }^{(11)} \mathrm{A}$ disposable reference electrode was applied to the forehead.

Recordings were produced while the patient was closing firmly in intercuspal position, on both preferred and non preferred side. The peak EMG muscle activity was recorded.

\section{Measuring the biting force:}

Recording maximum bite force was obtained by using Dataqua, Elektronikai Ltd Hungary. Its high precision Ultra-Miniature load cell and its electronic circuit for indicating force provide precise measurements. The Load Cell transducer was covered with putty rubber base dental impression material which was fitted to the occlusal surface of the patient's teeth, thus a reproducible bite position was obtained. The transducer was positioned between the occlusal surfaces in the second premolar, first molar region. Apiece of metal has the same dimensions of the load cell was covered by silicone putty and placed on the occlusal and on the same position of the opposite side. The patient was instructed to bite on the bite-force transducer as hard as possible for three seconds in centric relation and protrusive positions (edge to edge position of anterior teeth). The biting force measurement was performed three times for both right and left sides with a one-minute rest between trials.

\section{RESULT}

The results of electromyographic activity are presented in table (1 and 2). There was no significant increase in electromyographic activity in the masseter and temporalis muscle when using two different occlusal patterns in both preferred and non preferred sides.

Also, the result of maximum biting force revealed that there were no significant differences between the two different occlusal patterns(3).

Table (1) EMG activity (micro volt) of masseter

muscle using different occlusal pattern.

\begin{tabular}{|c|c|c|c|c|c|c|}
\hline & \multicolumn{2}{|c|}{ Bilateral balanced occlusion } & \multicolumn{2}{|c|}{ Lineal occlusion } & \multicolumn{2}{c|}{ Statistical value } \\
\cline { 2 - 7 } & Mean & \pm St d & Mean & \pm St d & t-value & p-value \\
\hline Preferred side & 352.0 & \pm 26.44 & 299.5 & \pm 30.9 & 5.90 & 0.09 \\
\hline Non-preferred side & 285.5 & \pm 16.0 & 250.0 & \pm 33.9 & 4.29 & 0.17 \\
\hline
\end{tabular}

Table (2) EMG activity (micro volt) of temporalis muscle using different occlusal pattern.

\begin{tabular}{|c|c|c|c|c|c|c|}
\hline & \multicolumn{2}{|c|}{ Bilateral balanced occlusion } & \multicolumn{2}{|c|}{ Lineal occlusion } & \multicolumn{2}{c|}{ Statistical value } \\
\cline { 2 - 7 } & Mean & \pm St d & Mean & \pm St d & t-value & p- value \\
\hline Preferred side & 300.0 & \pm 55.0 & 270.0 & \pm 32.5 & 5.90 & 0.11 \\
\hline Non-preferred side & 245.0 & \pm 43.0 & 245.0 & \pm 43.0 & 1.09 & 0.07 \\
\hline
\end{tabular}


Table (3) Effects of different occlusal pattern on maximum biting force ( $\mathrm{kg}$ ).

\begin{tabular}{|c|c|c|c|c|c|c|}
\hline & \multicolumn{2}{|c|}{ Bilateral balanced occlusion } & \multicolumn{2}{|c|}{ Lineal occlusion } & \multicolumn{2}{|c|}{ Statistical value } \\
\hline & Mean & \pm St d & Mean & \pm St d & t- value & $\mathrm{p}$-value \\
\hline Preferred side & 15.01 & \pm 0.187 & 14.34 & \pm 0.150 & 4.15 & 0.08 \\
\hline Non-preferred side & 13.49 & \pm 0.239 & 13.31 & \pm 0.220 & 5.14 & 0.27 \\
\hline
\end{tabular}

\section{DISCUSSION}

The result of the present study found that there is no statistical significant difference in the biting forces between balanced and lineal occlusion. This result comes in agreementwith many authors ${ }^{(12-14)}$. The authors found that there was nodifference in the maximum biting forces between balanced and lineal occlusion scheme. Also this comes in agreement withOhguri et al ${ }^{(15)}$ who compared the pressure values on the supporting tissue under a mandibular denture when crushing 3 different food (softfood, peanuts and carrots) with 3 different occlusal schemes of artificial posterior teeth (fully balanced occlusion, lineal occlusion, and monoplane occlusion), using a simulator with pressure transducers placed in the basal surface of a mandibular denture. The results demonstrated that with full balanced occlusion and lineal occlusion a large occlusal force is not needed for crushing hard food, and the stress to the supporting tissues is smaller than monoplane occlusion, but there is no difference in pressure values between balanced occlusion and lineal occlusion.

The line of the occlusal contact was placed in the mandibular denture as the mandibular dentures are almost always less stable than maxillary dentures.

The result of the present study found that there is no statistical significant different between full balanced occlusion and lineal occlusion. These results come in disagreement with the result of MohieEldin $^{(16)}$ the study indicated that the linealocclusion showed the lowest values for EMG activity than the full balanced occlusion. This difference may be due to the study was carried out on patients with two mandibular canines remaining. Whileall patient participated in the present study were completely edentulous.

\section{CONCLUSION}

The lineal occlusion does not affect the value of the maximum biting force and electromyographic activity when compared to the bilateral balanced occlusion.

\section{REFERENCES}

1. Palmer CA. Gerodontic nutrition and dietary counseling for prosthodontic patients. Dent Clin North Am. 2003;47:35571. [PubMed]

2. Winkler S.Essentials of Complete Denture Prosthodontics. 2nd ed. Delhi: AITBs Publishers; 2000.

3. Boucher CO.Prosthodontic Treatment for Edentulous Patients. 9th ed. Delhi: CBS Publishers; 1990.p. 119.

4. Stellingsma K, Slagter AP, Stegenga R, et al; Masticatory function in patients with an extremely resorbed mandibule restored with mandibular implant-retained over denture: comparison of three types of treatment protocols. JoralRehabil. 2005; 32:403-10.

5. Miyaura K. Morita M, Matuska y, Yamashita A, Watanabet. Rehabilitation of biting abilities in patients with different types of prosthes.JoralRehabil 2000;27:107:3-6.

6. Richter, EJ.; in vivo vertical forces on implants. Int.J. oral Maxillofac.implant. (1995): 10:p.p.99-108.

7. Fontijin-Tekamp FA, Slagter AP, Vander Bilt A, et al; Biting and chewing in overdentures, full dentures, and natural dentitions. J Dent Res. 2000; 79: 1519-1524.

8. Van Kampen FMC, vander Bitt A, Cune MS, FontijnTekamp Fa, Bosmanf. Masticatory Function with implantsupported overdentures J Dent REs 2004; 83:708-11. 
9. Van der Bilt, Van Kampen FM, Cune MS Masticatory Function with mandibular implant-supported overdentures Bitted with Different attachment types. EurJoral Sci. 2006; 114:191-196.

10. 10. Van der BiltA\&Fontijin-Tekamp FA. Comparison of single and multiple sieve methods for the determination of masticatory performance. Arch Oral Biol 2004b; 49: 193-8.

11. Ferrario, V F, Sforza C, Colombo A, Ciusa V: An electromyographic investigation of masticatory muscles symmetry in normo-occlusion subjects. Journal of Oral Rehabilitation.2000; 27: 33-40.

12. Schneider G \&Senger B. Clinical relevance of a simple fragmentation model to evaluate human masticatory per- formance J. Oral Rehabil 2002: 29: 731-6.

13. AbdeNaser S E EL-Gharbawy S H Halim M MIsmail S B. (1993): Astudy of stess transmission by distal extention removable prothesis constructed according to different concepts of design. Alex Dent J.18:p.p. 103-126

14. Clough HE, Knodle JM, Leeper SH, et al; J preosth Dent, 1983, 50: 176-179

15. Ohguri T, Kawano F, Ishikawa T, et al; Int J Prosthodont. 1999; 12: 353-8.

16. MohieEldin A Hoda. The influence of three occlusal schemes on the masticatory performance and electromyographic activity in overdenture wearers.Egyptian Dental Journal.2003; 49: 1257-64. 